\title{
STRATEGI KESIAPAN PEMBERIAN ASI EKSKLUSIF MELALUI BREAST CARE PADA IBU PRIMIGRAVIDA
}

\author{
Fitriani $^{1}$, Veni Nella Syahputri² \\ fitriani@utu.ac.id ${ }^{1}$,veninellasyahputri@utu.ac.id
}

\begin{abstract}
ABSTRAK
Pembentukan manusia berkualitas dimulai dari janin dalam kandungan, pemberian nutrisi dan juga pemberian ASI eksklusif termasuk kolostrum tanpa memberikan makanan serta minuman sampai usia 6 bulan kecuali obat. Pemberian ASI sangat penting untuk tumbuh kembang bayi secara optimal, baik secara fisik maupun mental serta kecerdasan. Breast care (perawatan payudara) merupakan bagian yang harus diperhatikan sebagai persiapan untuk menyusui nantinya karena payudara merupakan organ essensial penghasil ASI pada bayi. Sejalan dengan hal ini, ibu hamil membutuhkan dukungan serta edukasi tentang implementasi perawatan payudara sehingga memperdalam pengetahuan tentang perawatan payudara yang dapat memperlancar pengeluaran ASI (Kristiyanasari, 2009). Cakupan pemberian ASI eksklusif pada bayi di Kabupaten Aceh Barat pada tahun 2015 yaitu 55 \%, cakupan ini masih dibawah target sebesar $80 \%$, keadaan ini sangat penting perlu perhatian khusus dari pemerintah daerah agar cakupan ASI eksklusif meningkat.Desain penelitian ini bersifat observasional yaitu dengan intervensi pelatihan perawatan payudara (breast care) pada ibu hamil primigravida pada trisimister III dan penyuluhan tentang ASI eksklusif. Penelitian dilakukan di Kabupaten Aceh Barat dengan cakupan ASI eksklusif belum mencapai target. Hasil penelitian menunjukan bahwa $77.6 \%$ ibu hamil primigravida telah siap memberikan ASI ekslusif melalui breast care (perawatan payudara) yang diikuti dan diintervensi pada masa kehamilan trisimister III hingga ibu melahirkan sampai dengan masa nifas. Pemantauan selama empat minggu ke tempat domisili sampel dilakukan untuk menganalisa tingkat pemahaman ibu tentang implementasi breast care (perawatan payudara) yang disertai pemberian masukan tentang tahapan kerja sistematis oleh bidan terlatih dan peneliti. Dapat disimpulkan bahwa breast care (perawatan payudara) berperan penting dalam memperlancar ASI, mecapai target keberhasilan ASI ekslusif selama 6 bulan, serta berperan penting dalam meningkatkan persentase cakupan pemberian ASI ekslusif di kabupaten Aceh Barat.
\end{abstract}

\section{Kata Kunci : ASI Ekslusif, Breast Care (perawatan payudara), ibu hamil primigravida}

\section{PENDAHULUAN}

Pembentukan manusia berkualitas dimulai dimulai dari janin dalam kandungan, dengan memberi nutrisi pada ibu hamil yang dilanjutkan pada tahapan pemberian ASI eksklusif setelah bayi dilahirkan, yaitu memberikan Air Susu Ibu (ASI) saja termasuk kolostrum tanpa memberikan berbagai makanan lainnya serta minuman tambahan kepada bayi sejak dilahirkan sampai usia 6 bulan kecuali obat atas anjuran tenaga kesehatan. Pemberian ASI merupakan perilaku yang sangat penting sebagai penu jang tumbuh kembang bayi secara optimal, baik secara fisik maupun mental serta kecerdasan, oleh karena itu pemberian ASI perlu mendapat perhatian lebih dari para ibu dan tenaga kesehatan agar proses menyusui dapat terlaksana dengan benar (Depkes RI, 2005)

$$
\text { Data dari United Nations }
$$

Childrens Fund (UNICEF) menyatakan bahwa, 30.000 kematian bayi dan 10 juta 
kematian balita setiap tahunnya dapat dicegah dengan pemberian Air Susu Ibu (ASI) secara ekslusif, dari usia 0 - 6 bulan tanpa memberikan makanan serta minuman tambahan terhadap nutrisi bayi. UNICEF menyebutkan adanya bukti penelitian yang terbaru, oleh Jurnal Paediatrics, bahwa bayi yang diberikan susu formula memiliki resiko/peluang meninggal dunia pada bulan pertama kelahirannya 25 kali lebih tinggi jika dibandingkan dengan bayi yang disusui secara ekslusif. (Herger B, 2008)

Persentase Angka Kematian Bayi (AKB) di Indonesia masih tinggi, berdasarkan data dari Survei Kesehatan Dasar Indonesia (SDKI) jumlah kematian bayi telah menurun dari 34/1000 kelahiran hidup pada tahun 2007 menjadi 32/1000 kelahiran hidup pada tahun 2012, akan tetapi ini masih dibawah target yang ditentukan.

Pemberian ASI secara eksklusif selama enam bulan merupakan langkah yang sangat tepat dalam memenuhi kebutuhan nutrisi bayi. Air Susu Ibu (ASI) memang telah disiapkan untuk pertumbuhan dan perkembangan bayi manusia. Segera menyusui pada satu jam pertama saat bayi baru lahir terbukti dapat menyelamatkan satu juta nyawa bayi, hal ini merupakan suatu pernyataan berdasarkan bukti ilmiah yang mengandung pesan moral sangat penting bagi semua orang demi kelangsungan hidup dan kesehatan bayi kita (Soetjiningsih, 2007)

Berbagai penyebabkan tidak terlaksananya pemberian ASI eksklusif dengan baik. Salah satunya adalah kesalahan pada saat tata laksana laktasi, yang menyebabkan menurunannya produksi ASI. Serta sebagian besar ibu yang tidak menyusui bayinya, bukan karena gangguan fisik melainkan lebih banyak karena kesalahan pada saat tata laksana laktasi (Carlson, 2008).

Breast care (perawatan payudara) merupakan bagian harus diperhatikan sebagai persiapan untuk menyusui nantinya, hal ini karena payudara merupakan organ essensial penghasil ASI pada bayi, masalah utama dan prinsip yaitu ibu - ibu membutuhkan bantuan, informasi dan dukungan agar merawat payudara pada saat hamil untuk mempersiapkan ASI saat melahirkan sehingga menambah keyakinan bahwa mereka dapat menyusukan bayinya dengan baik serta mengetahui fungsi dan manfaat perawatan payudara pada saat hamil.

Apabila seorang ibu hamil tidak melakukan breast care dengan baik maka akan berdampak terhadap tidak lancarnya ASI. Anjuran Perawatan payudara pada ibu hamil sebaiknya dilakukan pada usia kehamilan 18 minggu - 40 minggu (Trimester II dan III) dan bukan sesudah persalinan dilakukan. (Ronald, 2011)

Primigravida adalah seorang wanita yang hamil untuk pertama kalinya. Dimana pada masa ini pengetahuan ibu tentang kesehatanibu dan anak sangatlah kurang sehingga perlu diberikan banyak informasi tentang Kesehatan Ibu dan Anak (KIA) terutama masalah perawatan payudara karena baru pertama kali akan menjadi seorang ibu menyusui. (Varney, 2009).

Kasus Kematian Bayi di provinsi Aceh dalam waktu enam tahun terakhir cenderung mengalami peningkatan. Jumlah kematian Bayi di Aceh pada tahun 2015 adalah 1.179 jiwa atau 12/1.000 Lahir Hidup (LH). Kabupaten /kota yang menyumbang AKB tertinggi pada tahun 2015 yaitu kabupaten Aceh Barat sebesar 27/1000 LH, sedangkan AKB terendah terdapat di kota Banda Aceh sebesar 3/1.000 kelahiran hidup ( Profil Dinas Kesehatan Aceh, 2016).

Capaian pemberian ASI eksklusif pada bayi di Kabupaten Aceh Barat pada tahun 2015 yaitu $55 \%$, capaian ini masih dibawah target SPM yaitu sebesar $80 \%$, hal ini perlu mendapatkan perhatian khusus dari pemerintah daerah agar cakupan pemberian ASI eksklusif 
meningkat, mengingat besarnya manfaat keberhasilan pemberian ASI eksklusif, khususnya untuk kesehatan bayi. Berdasarkan permasalahan diatas penulis tertarik mengkaji secara ilmiah "Strategi Kesiapan Pemberian ASI eksklusif Melalui Breast Care Pada Ibu Primigravida"

Tujuan penelitian ini untuk meningkatkan pemberian ASI eksklusif melalui perawatan payudara dimasa kehamilan, meningkatkan pengetahuan sasaran selama kehamilan tentang bahaya atau dampak bayi tidak diberikan ASI secara eksklusif

\section{METODE PENELITIAN}

Disain penelitian ini bersifat observasional yaitu dengan intervensi pelatihan perawatan payudara (breast care) pada ibu hamil primigravida pada trimister III dan penyuluhan tentang tata cara pemberian ASI eksklusif. Penelitian dilakukan di wilayah Kabupaten Aceh Barat dengan cakupan ASI eksklusif belum mencapai target.

Sampel dalam penelitian ini adalah seluruh ibu hamil Primigravida dengan umur kehamilan memasuki trisemester III di seluruh Gampong (desa) yang tersebar di Kabupaten Aceh Barat. Semua sampel penelitian di ikuti dari sejak ibu hamil memasuki trisemester III sampai dengan masa nifas

Intervensi meliputi :

1. Melakukan pelatihan perawatan payudara pada ibu hamil primigravida trimester III yang dilakukan oleh tenaga terlatih sebanyak 4 kali selama 4 minggu secara berturut- turut. Seminggu sebelum pelaksanaan pelatihan,ibu hamil diberikan buku saku "Tata Cara Breast Care". Pada saat pelaksanaan pelatihan menggunakan alat bantu kit konseling (boneka payudara), vidio perawatan payudara, poster dan leaflet agar mudah dipraktikan oleh peserta.

2. Buku saku "Tata Cara Breats Care", disusun khusus oleh penulis berdasarkan referensi tatalaksana perawatan payudara.

3. Tenaga pelatihan breast care adalah bidan yang sudah mendapatkan pelatihan managemen laktasi dalam kurun waktu 3 tahun belakangan.

\section{HASIL PENELITIAN \\ Minggu Pertama Pelaksanaan (01 April 2018)}

Sebelum melaksanaan kegiatan inti, peneliti memberikan pre-test dengan menanyakan 10 pertanyaan dari kuesioner kepada sasaran penelitian yaitu ibu hamil primigravida. Adapun pertanyaan yang ditanyakan meliputi uji pengetahuan para peserta khususnya tentang perawatan payudara melalui pelatihan breast care dan kesiapam pemberian ASI eksklusif, sedangkan post-test akan diberikan pada minggu terakhir pelaksanaan penelitian. Pada minggu pertama pelaksanaan penelitian, peneliti sekaligus panitia menghadirkan bidan sebagai tenaga terlatih dan didampingi oleh ketua pelaksana penelitian dalam memberikan edukasi. Seluruh peserta yang berhadir diminta untuk menandatangi absen sebagai bukti kehadiran atas partisipasi kegiatan. Bentuk komunikasi interpersonal dan informatif diterapkan oleh pemateri. Penyampaian materi disampaikan melalui teori sekaligus praktik langsung pada kit konseling yang telah disediakan oleh tim peneliti. Secara garis besar, materi terdiri dari pemaparan konsep ASI, pentingnya ASI eksklusif bagi perkembangan bayi, faktor - faktor yang mempengaruhi berhasilnya ASI ekslusif, serta konsep breast care beserta manfaat dan prosedur pelaksanaannya. Untuk memperjelas pemahaman peserta, bidan terlatih sebagai pemateri memperagakan langsung tahapan perawatan payu dara melalui breast care dengan menjelaskan alat dan bahan yang dibutuhkan terlebih dahulu. Adapun tahapan pelaksanaan breast care terdiri dari: (1) Melakukan pengompresan kedua puting dengan menggunakan minyak 
kelapa atau baby oil selama 3-5 menit, kemudian kapas diangkat sambil terus membersihkan kotoran yang menempel diputing ibu. (2) Telapak tangan diletakkan diantara kedua payudara dengan posisi ujung jari menghadap kebawah. Kemudian telapak tangan ditarik ke atas melingkari payudara sambil menyangga payudara, serta tangan dilepas dengan gerakan cepat kearah depan. Gerakan ini minimal dilakukan 20 kali dengan tujuan menjaga kekenyalan dan kekencangan payudara. (3) Melakukan pengurutan payudara. (4) Tangan kanan penyangga payudara kanan, kemudian sisi luar tangan kiri mengurut payudara kearah puting susu. (5) Membasuh payudara dengan air hangat dan air dingin secara bergantian dan dikerjakan berulang ulang lalu keringkan dengan handuk. (6) Dilakukan perangsangan pada puting susu dengan menggunakan waslap atau handuk kering yang digerakkan keatas dan bawah beberapa kali yang bertujuan untuk meningkatkan erektilitas puting susu dan mengurangi insiden puting terluka. Partisipasi aktif dari ibu hamil primigravida ditunjukan dengan pergantian seluruh peserta yang berjumlah $30 \mathrm{ibu}$ hamil primigravida memperagakan perawatan payudara melalui breast care pada kit konseling. Praktik langsung diyakini dapat meningkatkan kemampuan seseorang dalam mengingat kegiatan yang dilakukan. Pelatihan ini dengan tujuan untuk meningkatkan pemahaman dan kemandirian ibu hamil primigravida tentang efektivitas pemberiaan ASI ekslusif selama $0-6$ bulan serta menumbuhkan kesadaran ibu dalam melakukan perawatan payudara melalui breast care sebagai bentuk kesiapan kesiapan pemberian ASI setelah melahirkan. Secara teoritis, kesiapan pemberian ASI eksklusif ditandai dengan keluar ASI dengan lancar, tidak lecetnya puting, posisi yang nyaman bagi ibu dan bayi sehingga bayi bisa menghisap dengan puas. Sampel dalam penelitian ini akan diikuti hingga melahirkan yang ditergetkan lebih kurang dua bulan kedepan. Data hasil penelitian disajikan secara deskriptif untuk menjelaskan proses dan intervensi pelaksanaan pelatihan.

\section{Minggu Kedua Pelaksanaan (08 s/d 13 April 2018)}

Bukti tindaklanjut dari minggu pertama, peneliti bersama bidan terlatih mengunjungi rumah ibu hamil primigravida untuk meninjau implementasi breast care. Kegiatan pada minggu kedua ini dilakukan didalam ruangan tertutup dikarenakan ibu hamil primigravida harus memperagakan langsung perawatan payudara. Perawatan payudara melalui breast care disarankan untuk dilakukan secara rutin yaitu sehari sekali. Dari 30 ibu hamil primigravida yang diikuti pada minggu kedua pelaksanaan, $25 \mathrm{ibu}$ diantaranya sudah faham, lancar dan rutin melakukan breast care, sedangkan 5 ibu lainnya masih memerlukan arahan yang lebih lanjut dari bidan terlatih dan tim peneliti. Dalam melaksanakan kunjungan ke rumah rumah, tim peneliti membawa dan memperlihatkan kembali kit konseling yang terdiri dari patung, pompa ASI, botol ASI, wadah dan waslap sebagai perangkat pendukung perawatan payudara melalui breast care.

\section{Minggu Ketiga Pelaksanaan (15 s/d 20 April 2018)}

Sebagaimana kegiatan pada minggu kedua, minggu ketiga ini merupakan lanjutan pelatihan breast care dimana bidan terlatih dan tim peneliti kembali mengunjungi ibu - ibu primigravida di rumahnya. Kegiatan yang sama juga dilakukan pada minggu ini dimana para sasaran penelitian diminta untuk memperagakan langsung perawatan payudara melalui breast care. Berdasarkan hasil tinjauan langsung peneliti, $28 \mathrm{ibu}$ hamil primigravida dikategorikan cukup siap dan benar melakukan breast care 
melalui tahapan yang sudah dijelaskan sebelumnya. Namun, 2 ibu belum melakukan perawatan payudara secara sistemastis.

Minggu Keempat Pelaksanaan (22 s/d 27 April 2018)

Sebagai minggu terakhir tinjauan pelaksanaan breast care ke rumah ibu hamil primigravida, tim peneliti tmemberikan post-test kepada ibu hamil primigravida. Post test ini bertujuan untuk mengukur tingkat pengetahuan ibu setelah mengikuti segenap materi, praktik langsung tenaga terlatih, dan praktik mandiri. Pada minggu keempat, peneliti menyiapkan video implementasi breast care pada perangkat telepon genggam dengan tujuan mengarahkan kembali pemahaman $\mathrm{ibu}$ - ibu hamil primigravida tentang tahapan pelaksanaan secara sistemastis. Hal ini terbukti sangat berpengaruh dalam pelaksanaan breast care. Meskipun pemutaran video telah dilakukan pada minggu pertama pelatihan, namun bimbingan dan arahan dari berbagai sumber tetap dibutuhkan untuk menunjang keberhasilan target yang akan dicapai. Seluruh ibu hamil primigravida yang dikunjungi pada minggu keempat ini telah berhasil melakukan perawatan payu dara melalui breast care secara sistematis.

\section{Pemantauan kesiapan dan keberhasilan breast care pada ibu hamil primigravida.}

Berdasarkan hasil pemantauan terhadap. 30 sampel penelitian dengan mengikuti dan peninjauan langsung setelah masa melahirkan ke tempat domisili masing - masing menunjukkan sebagai berikut :

Gambaran karakteristik responden yang terdiri dari umur ibu, pendidikan ibu, dan pekerjaan ibu primigravida dapat dilihat distribusinya pada Tabel 1.
Tabel 1

Karaketristik sosiodemografi ibu hamil primigravida

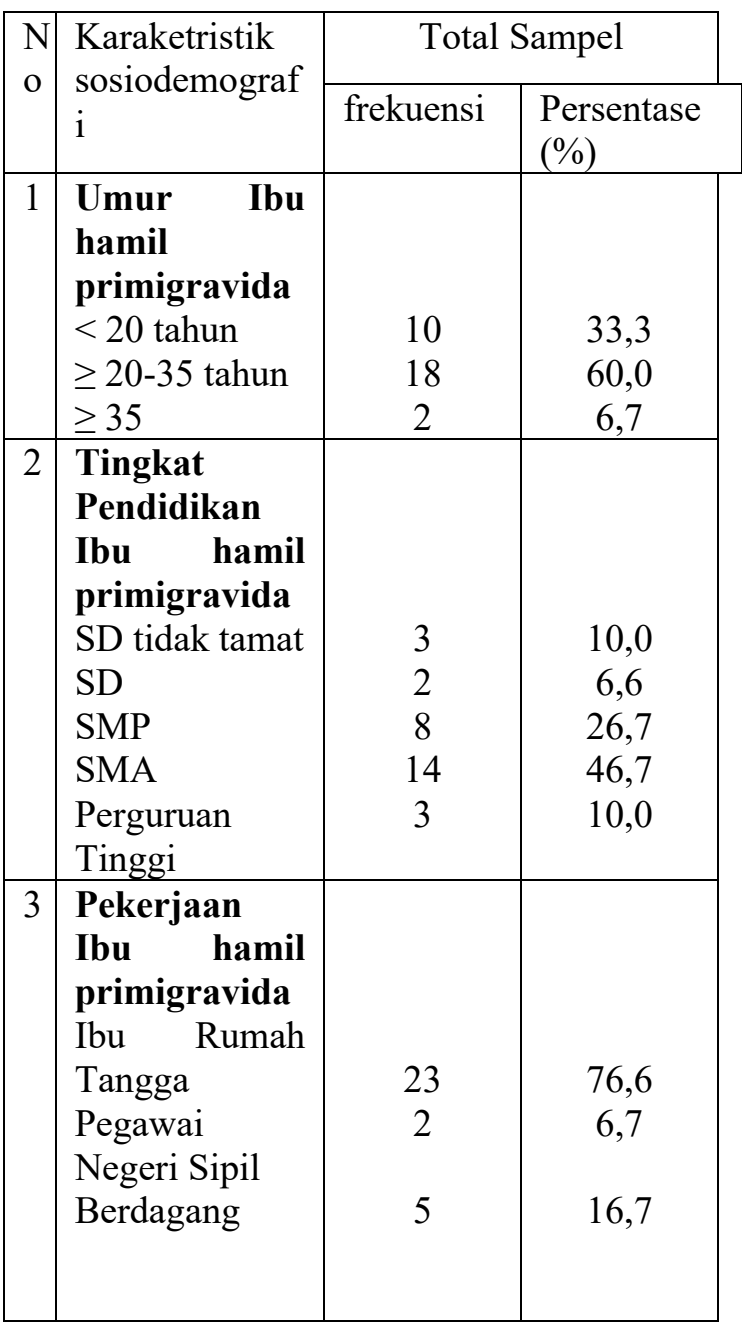

Dari tabel diatas dapat diketahui bahwa sebahagian besar ibu berumur antara 20-35 tahun (60,0\%). Sebanyak 14 orang ibu hamil primigravida dengan tingkat pendidikan SMA $(46,7 \%)$, dan rata - rata ibu bekerja sebagai ibu rumah tangga (76,6\%).

Berdasarkan hasil intervensi dan pemantauan langsung ke tempat domisili sampel penelitian, maka terdapat dua kelompok ibu hamil primigravida dengan kategori siap memberikan ASI eksklusif pada bayinya dan tidak siap memberikan ASI eksklusif. Pengumpulan data yang berkaitan dengan kesiapan ibu hamil 
primigravida dalam memberikan ASI ekslusif melalui breast care ditentukan dengan merujuk kepada indikator pada tabel 2 berikut:

Tabel 2:

Indikator Kesiapan Pemberian ASI ekslusif melalui Breast Care

\begin{tabular}{|l|l|}
\hline No & Indikator \\
\hline 1 & $\begin{array}{l}\text { Keberhasilan dalam melakukan } \\
\text { Inisiasi Menyusui Dini (IMD) }\end{array}$ \\
\hline 2 & Putting ibu yang tidak lecet \\
\hline 3 & $\begin{array}{l}\text { Ibu nyaman menyusui dengan } \\
\text { berbagai posisi }\end{array}$ \\
\hline 4 & Bayi puas dalam minum ASI \\
\hline 5 & Keluarnya ASI dengan lancer \\
\hline
\end{tabular}

Merujuk kepada indicator diatas, maka hasil penelitian tentang strategi kesiapan pemberian ASI ekslusif oleh ibu hamil primigravida melalui breast care adalah sebagai berikut:

Tabel 3:

Kesiapan Pemberian ASI melalui Breast Care

\begin{tabular}{|l|l|l|c|}
\hline No & Kategori & $\begin{array}{l}\text { Frekuensi } \\
\text { (n) }\end{array}$ & $\begin{array}{l}\text { Persentase } \\
(\%)\end{array}$ \\
\hline 1 & Siap & 23 & 76,6 \\
\hline 2 & Tdk Siap & 7 & 23,3 \\
\hline & & 30 & $100 \%$ \\
\hline
\end{tabular}

Table diatas menunjukkan bahwa sebanyak $76.6 \%$ ibu hamil primigravida yang telah dilatih dan diintervensi terbukti siap memberikan ASI ekslusif melalui breast care (perawatan payudara). Pemantauan hasil kesiapan pemberian ASI dilakukan setelah ibu melahirkan hingga masa nifas. Sebanyak 23 ibu hamil yang dikategorikan siap tersebut telah melakukan langkah - langkah breast care (perawatan payudara) dengan benar dan sistematis sehingga berhasil melakukan Inisiasi Menyusui Dini (IMD), puting ibu tidak lecet, ibu merasa nyaman saat menyusui, bayi terlihat puas serta lancarnya ASI ibu. Sedangkan 7 orang ibu hamil primigravida lainnya (23.3\%) diklasifikasikan sebagai kelompok yang tidak siap dikarenakan adanya kejadian anemia pada ibu hamil sehingga ASI tidak lancar (2 orang ibu), tidak rutin melakukan breast care yang menyebabkan gagalnya IMD ( 1 orang ibu), riwayat keturuan tidak munculnya puting sehingga puting ibu lecet saat menyusi ( 2 orang ibu), serta asupan gizi ibu selama hamil juga menyumbang angka kegagalan pada 2 ibu hamil primigravida dalam mencapai kesiapan pemberian ASI eksluisif melalui breast care (perawatan payudara).

\section{BAB VII KESIMPULAN DAN SARAN}

\subsection{Kesimpulan}

1. $76.6 \%$ ibu primigravida di Kabupaten Aceh Barat telah siap memberikan ASI ekslusif melalui breast care.

2. Breast Care (perawatan payudara) memberikan konstribusi positif terhadap keberhasilan cakupan pemberian ASI di kabupaten Aceh Barat.

3. Edukasi dan pendampingan terbukti berpengaruh secara signifikan dalam mengimplementasikan Breast Care (perawatan payudara).

\subsection{Saran}

1. Disarankan agar kader melalukan pengontrolan dan pendampingan kepada ibu hamil primigravida dalam melalukan breast care (perawatan payudara) dengan membuat kartu control sebanyak 2 kali dalam seminggu.

2. Diharapkan bahwa ibu hamil primigravida melakukan perawatan payudara secara rutin.

3. Disarankan kepada dinas kesehatan agar mencanangkan program perawatan payudara kepada ibu hamil primigravida sebagai bentuk edukasi kesehatan mendasar bagi seorang ibu hamil pertama. 


\section{Daftar Pustaka}

Asrinah, 2010, Asuhan Kebidanan

Masa Kehamilan, Yogyakarta:

Graha Ilmu

Departemen Kesehatan RI, 2005,

Strategi Nasional Peningkatan

Pemberian Air Susu Eksklusif. Jakarta.

Depkes RI, 2001, Pedoman Penyelenggaran Pelatihan

Konseling Menyusui Dan Pelatihan Fasilitator Konseling Menyusui : Jakarta

Carlson, C 2008. Ilmu Kesehatan Masyarakat untuk Mahasiswa Kebidanan, Jakarta : EGC

Kristiyanasari, 2009. ASI, Menyusui dan Sadari. Yogyakara: Nuha Medika

Ronald, 2011. Pedoman dan Perawatan Kehamilan yang sehat dan Menyenangkan, Bandung.Nuasa Aulia

Roesli, 2005, Mengenal ASI Eksklusif.Jakarta :Agrimidea

Herger B, et al.2008.Bedah ASI. Jakarta : Balai Penerbit FKUI

Kementerian Kesehatan. Riset Kesehatan Dasar. Badan penelitian dan Pengembangan Kesehatan

Kementerian Kesehatan,2013. Jakarta Varney, 2007. Buku Ajar Asuhan Kebidanan, Jakarta : EGC

Soetjiningsih, 1997, Air Susu Ibu Petunjuk Untuk Tenaga Kesehatan. Jakarta : EGC

Wiji, 2013. ASI dan panduan ibu menyusui. Yogyakarta : Nuha Medika

Profil Dinas Kesehatan Aceh, Profil Dinas Kesehatan Aceh, 2016

Perinisia. 2001, Bahan Bacaan Manajemen Laktasi, Jakarta : Perkumpulan Perinatologi 
